
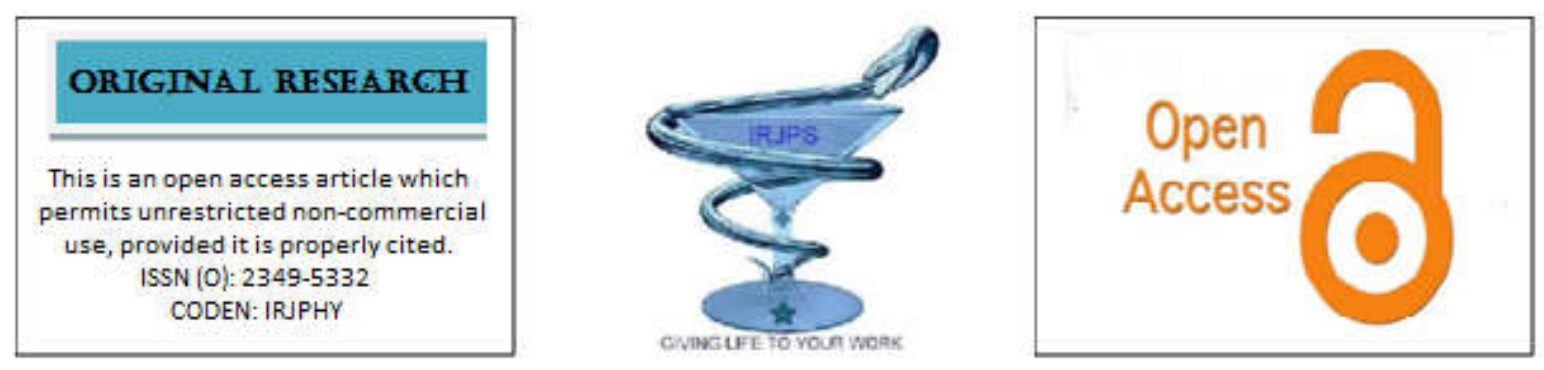

\title{
Evaluation and appraisal of services provided by drug information centre in a tertiary care teaching hospital
}

\author{
Binu K. M ${ }^{1 *}$, Divya Pramod ${ }^{1}$, H.Doddayya ${ }^{1}$. \\ ${ }^{1}$ Department of Pharmacy Practice, NET Pharmacy college, Raichur-584103 Karnataka, India
}

Submitted on: 12.05.2020;

Revised on: 14.06.2020;

Accepted on: 27.06.2020

\begin{abstract}
Background: Drug information service is a specialized service provided by pharmacists to enhance drug knowledge, empower rational prescribing, and reduce medication errors. This service is provided in response to the queries sought by allied health professionals in addressing drug - related problems pertaining to pharmacotherapy and medicine management issues of patients.

Study Objective: To evaluate and assess the services provided by drug information centre.

Method: Retrospective study was conducted for a period of six months on evaluation of queries which were documented during February 2010 to December 2018. Quality of service provided by DIC was assessed from the receiver's perspective.

Results: A total of 642 queries were documented in which majority of the queries were received in the year 2018(35.2\%) and most of the queries were asked from General medicine department (31.4\%). $71.33 \%$ of queries were received during ward rounds. Most of the queries were to update knowledge (62. 94\%).Seventy of the health care professional responded to the feedback questionnaire. Respondents were aware of the existence of drug information center was 54and 37utilized the services of the center. Among the respondents who utilized the services 28 received the appropriate answer within time.

Conclusion: Drug information services provided by the department of pharmacy practice, were useful to the health care professionals in updating their knowledge and providing better patient care. There is need to bring greater awareness about DIC, its services in and around the hospital and among physicians, pharmacists, nurses and patients.
\end{abstract}

KEYWORDS: Drug information services, Queries, pharmacists.

Correspondence to author: Mr. Binu K. M

Email: binum2@gmail.com

Mobile: 8971698943
Indian Research Journal of Pharmacy and Science; 25(2020)2258-2265;

Journal Home Page: https://www.irjps.in

DOI: $10.21276 /$ irjps.2020.7.2.17 


\section{INTRODUCTION}

Drug information service is a specialized service provided by pharmacists to enhance drug knowledge, empower rational prescribing, and reduce medication errors. This service is provided in response to the queries sought by allied health professionals in addressing medication - related problems pertaining to pharmacotherapy and medicine management issues of patients. One of the most important aspects of drug information is to be unbiased in its contents. Thus, the unbiased nature of information is of paramount importance to enhance patient outcomes and reduce adverse drug reactions (ADRs) $)^{1}$. The active intervention of pharmacist can provide more information on the patient safety and to improve quality of life. ${ }^{2}$

Due to information explosion, vast availability of literature and lack of time; health care professionals are not in a position to update their knowledge. Though there are prescription and nonprescription drugs; the free availability of drugs, irrational drug use, iatrogenic diseases, antibiotic resistance, adverse drug reactions and events are very common in India. Drug information Centers (DICs) mainly provide information mainly to healthcare professionals and general public with information about all aspects of drug. Clinical pharmacist involvement will help clinicians to understand about new drugs for which there is increasing demand for independent, unbiased information about new drugs for a better patient care ${ }^{3}$. The provision of medical information is one of the most fundamental responsibilities of pharmacist. The information may be either patient specific, as an integral part of pharmaceutical care, or relative to the group of patients, such as development of therapeutic guideline, publishing the electronic newsletter, or updating the website. ${ }^{2}$

In India, the concept of rational drug use is yet a long way to go. Lack of unbiased drug information and lack of time are some of the factors that makes the physicians unable to update their knowledge about drugs which have resulted in an increasing demand for independent and unbiased information about drugs for better patient care. It is important, to periodically evaluate the mode of functioning and quality of the services provided by the center, so that necessary modifications can be made for better functioning ${ }^{4}$.

The aims of drug information services are to promote safe, effective and economic use of medicinal products by the provision of accurate, current, independent, evaluated information and advice. The main function of drug information center is to provide the information for improving of patient care $^{5}$. Most developing countries suffer from lack of adequate drug information due to limited availability of current literature and also poor documentation and dissemination of what little information is available ${ }^{6}$.

Information is key to preventing medication errors. Such information leads to enhanced quality of patient care and thus improved patient outcome .Poor drug regulation and lack of independent unbiased information are the main contributing reason for irrational drug use in India .About $40 \%$ of the health care services budget is consumed by medicines and with a limited resources available, it is essential to promote rational drug use. ${ }^{7}$ Drug information service describes activities undertaken by pharmacists in providing information to optimize drug use. ${ }^{6}$ As pharmacist have become increasingly involved in influencing prescribing, it is important that they provide unbiased evidence based drug information to prescribers. ${ }^{8}$

To maintain consistency in the service provided and for better functioning of the center, it is important to evaluate the functioning and quality of the services provided by the center at constant intervals. ${ }^{9}$ Improper functioning of the drug information center may contribute to poor patient outcomes in terms of health and economics due to provision of biased and limited drug information. ${ }^{10}$

In view of above facts, the study entitled "Evaluation and appraisal of Services provided by drug information Centre in a Tertiary Care Teaching Hospital" was taken. This will help to assess and improve the services provided by drug information centre at a teaching hospital.

\section{MATERIAL AND METHODS}

The study was carried out for a period of six months. A retrospective study was carried out by evaluating drug information request forms which were documented during February 2010 to December 
2018. The study was started after taking consent from respective authorities.

\section{Inclusion Criteria:}

- Queries received during February 2010 to December 2018

\section{Exclusion Criteria:}

- Queries received after December 2018

- Query which contains missed information A total of 642 queries were documented from February 2010 to December 2018.The documented queries were evaluated on the basis of parameters such as year wise distribution of queries, department wise distribution of queries, purpose of enquiry, mode of request, type of query, time frame to answer the query and sources used to answer the query were assessed. Quality of service provided by drug information centre was assessed from the receiver's perspective.The obtained data is analysed and assessed in accordance with the proper guidelines.

\section{RESULTS AND DISCUSSION}

A total of 642 queries documented during February 2010 to December 2018 were evaluated

Figure 4 reveals that the number of queries received by the drug information center is increasing since 2010 to 2014 but there has been a slight decrease in number of queries on the preceding year and it has been increased with a maximum of 226 queries in the year 2018. Most of the queries was from General medicine department (31.4\%) followed by others (28.6\%), Gynecology (11.6\%), surgery $(9.96 \%)$, pediatrics $(9.6 \%)$ and orthopedics $(8 \%)$ as illustrated in figure 5. Maximum number of queries were received during ward rounds $(71.33 \%)$ followed by direct access $(28.66 \%)$ shown in figure 6 and figure 7 debits that more number of queries were asked for the purpose of updating their knowledge $(62.9 \%)$ and for better patient care $(37.0 \%)$.

Table 1depicts the categorization of the received queries, most number of queries were about the drug, its availability in market, disease, signs \& symptoms etc. which are included in others $(30.6 \%)$ followed by pharmacokinetics of the drug (19.31\%), indication of the drug (14.64\%), Dose and administration (12.77\%), drug-drug interaction $(10.90 \%)$, adverse effects $(8.56 \%)$, toxicology $(3.73 \%)$.

Table 2 shows that the main sources used to answer the queries was primary source which include original research articles (34.2\%) followed by others (31.4\%), secondary source includes PubMed, Medline, databases, Cochrane library (18.3\%) and tertiary sources like textbooks Micromedex etc. $(15.8 \%)$.

The main sources used to answer the queries was primary source which include original research articles (34.2\%) followed by others (31.4\%), secondary source includes PubMed, Medline, databases, Cochrane library (18.3\%) and tertiary sources like textbooks Micromedex etc. (15.8\%) which are shown in table 3.

Table 4 depicts that forty questions were distributed to the clinicians and postgraduate trainees of different departments of the hospital for their feedback, of which, all $70(100 \%)$ responded $.54(77.1 \%)$ respondents were aware of the existence of drug information center and 37(68.5\%) utilized the services of the center. Among the respondents who utilized the services 28(51.8\%) received the appropriate answer within the acceptable time, but $9(16.6 \%)$ of them did not receive the answer within the acceptable time. Thirty-seven (68.5\%) of the respondents received the appropriate answer. No one was aware of the online drug information system existing in the hospital and also no one utilized this facility. Seventeen $(31.4 \%)$ of the respondents rated the performance of the drug information center as good, $22(40.7 \%)$ as satisfactory and $15(27.7 \%)$ suggested that the center requires improvement in its services. Some of the suggestions to improve the performance of the drug information center were to provide information on drugs recently introduced into the market and to extend the drug information services round the clock. 


\section{TABLES}

Table 1: Types of queries $(n=642)$

\begin{tabular}{|c|c|c|c|}
\hline SI. No & Types of query & No of queries & Percentage (\%) \\
\hline 1 & indication of drug & 94 & 14.64 \\
\hline 2 & Dose\& administration & 82 & 12.77 \\
\hline 3 & Drug-drug interaction & 70 & 10.90 \\
\hline 4 & Adverse effects & 55 & 8.56 \\
\hline 5 & pharmacokinetics & 124 & 19.31 \\
\hline 6 & toxicology & 24 & 3.73 \\
\hline 7 & others & 193 & 30.06 \\
\hline
\end{tabular}

Table 2: Time frame to reply $(n=642)$

\begin{tabular}{|c|c|c|c|}
\hline SI. No & Time frame to reply & No of queries & Percentage (\%) \\
\hline 1 & Immediately & 128 & 19.9 \\
\hline 2 & Within a day & 172 & 26.7 \\
\hline 3 & Within a week & 342 & 53.2 \\
\hline
\end{tabular}

Table 3: Sources used to answer the Query $(n=642)$

\begin{tabular}{|c|c|c|c|}
\hline Sl. No & Sources used & No of queries & Percentage (\%) \\
\hline 1 & Primary & 220 & 34.2 \\
\hline 2 & Secondary & 118 & 18.3 \\
\hline 3 & Tertiary & 102 & 15.8 \\
\hline 4 & Others & 202 & 31.4 \\
\hline
\end{tabular}


Table 4: Feedback Questionnaire

\begin{tabular}{|c|c|c|c|c|c|}
\hline \multicolumn{2}{|c|}{$\begin{array}{l}\text { FEEDBACK } \\
\text { QUESTIONS }\end{array}$} & $\begin{array}{c}\text { YES } \\
(n=54)\end{array}$ & PERCENTAGE & NO & PERCENTAGE \\
\hline \multicolumn{2}{|c|}{$\begin{array}{l}\text { Are you aware of the drug } \\
\text { information services in } \\
\text { our hospital? }\end{array}$} & 54 & 77.1 & 16 & 22.8 \\
\hline \multicolumn{2}{|c|}{$\begin{array}{c}\text { Have you utilized the drug } \\
\text { information services any } \\
\text { time? }\end{array}$} & 37 & 68.5 & 33 & 61.1 \\
\hline \multicolumn{2}{|c|}{$\begin{array}{l}\text { Have you received the } \\
\text { answer in time? }\end{array}$} & 28 & 51.8 & 9 & 16.6 \\
\hline \multicolumn{2}{|c|}{$\begin{array}{l}\text { Have you received the } \\
\text { appropriate answer? }\end{array}$} & 37 & 68.5 & 0 & 0 \\
\hline \multicolumn{6}{|c|}{ If no, the reason was, the information was, } \\
\hline Outdated & \multicolumn{2}{|c|}{ Too extensive } & \multicolumn{2}{|l|}{ Not relevant } & Others \\
\hline- & \multicolumn{2}{|c|}{$12(36.3 \%)$} & \multicolumn{2}{|l|}{-} & $21(33.6 \%)$ \\
\hline \multicolumn{2}{|c|}{$\begin{array}{l}\text { Are you aware of the online } \\
\text { drug information system } \\
\text { existing in our hospital? }\end{array}$} & - & - & 32 & 45 \\
\hline \multicolumn{2}{|c|}{$\begin{array}{l}\text { Have you utilized this } \\
\text { facility? }\end{array}$} & - & - & 32 & 45 \\
\hline \multicolumn{2}{|c|}{$\begin{array}{l}\text { Do you think that the drug } \\
\text { information service provided } \\
\text { by the department is useful } \\
\text { and helps in providing better } \\
\text { patient care? }\end{array}$} & 52 & $74.2 \%$ & - & - \\
\hline \multicolumn{6}{|c|}{ How do you rate the existing drug information system in our hospital? } \\
\hline Good & & \multicolumn{2}{|c|}{ Satisfactory } & \multicolumn{2}{|c|}{ Needs Improvement } \\
\hline 17 & & \multicolumn{2}{|r|}{22} & \multicolumn{2}{|r|}{15} \\
\hline
\end{tabular}




\section{FIGURES}

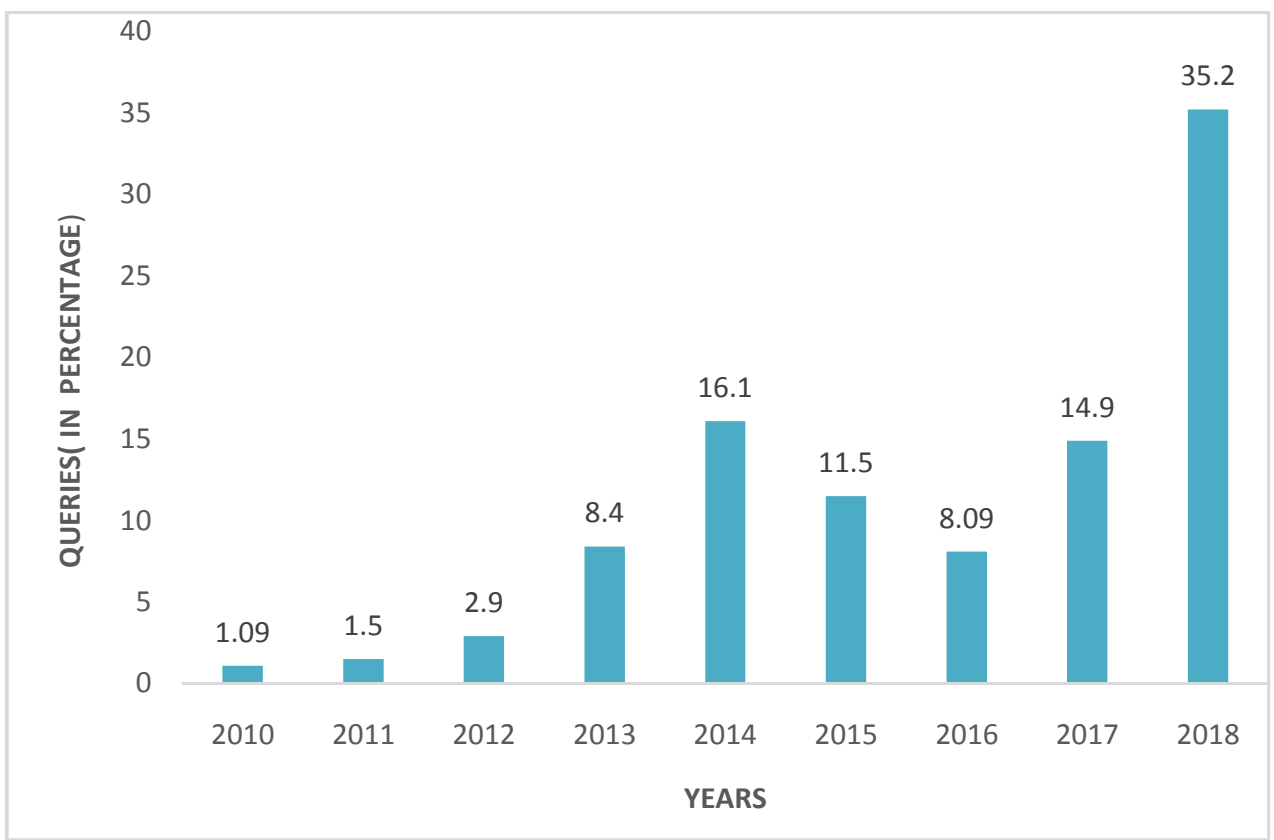

Figure 1: Year-wise distribution of queries $(n=642)$



Figure 2: Department wise distribution of queries $(n=642)$ 


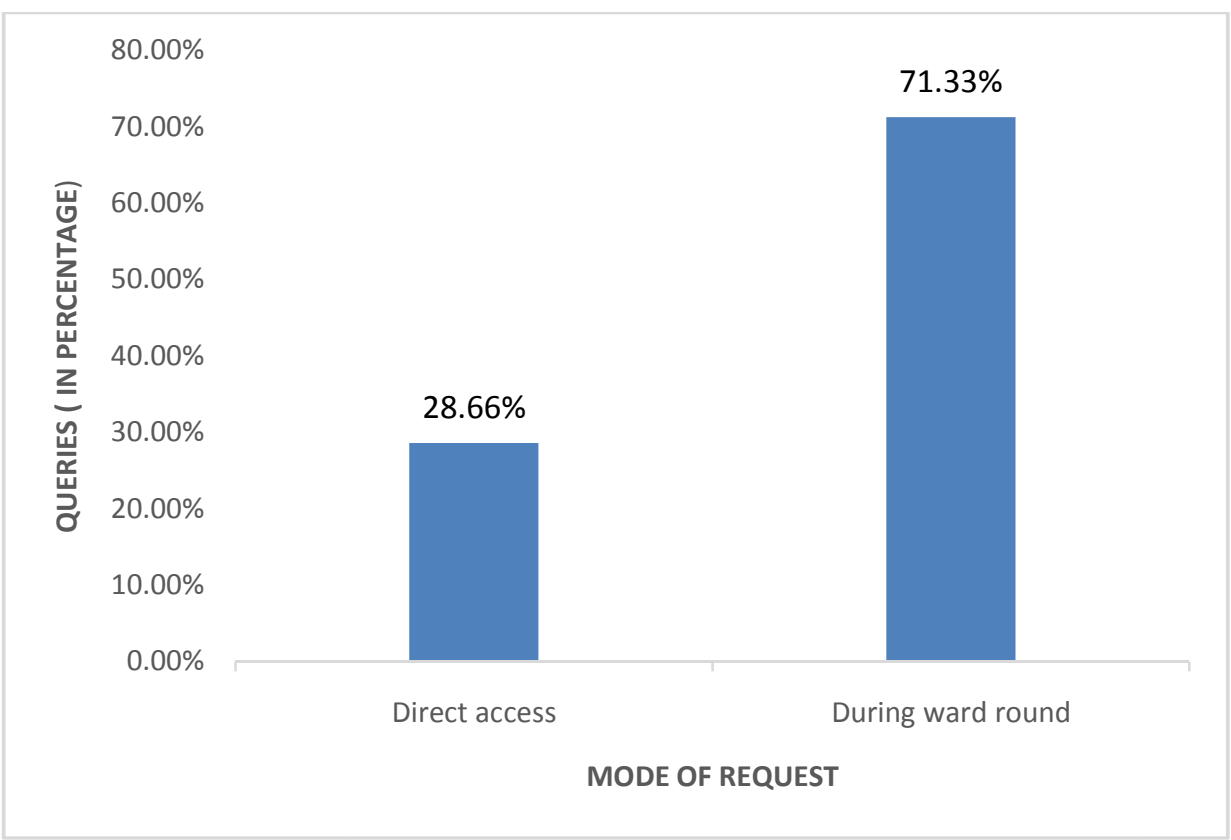

Figure 3: Mode of request $(n=642)$



Figure 4: Purpose of the query $(n=642)$ 


\section{ACKNOWLEDGEMENT}

We express our sincere thanks to Dr. Ashok Mahendrakar, Medical Superintendent, NMCH\&RC, Raichur who had permitted us and provided us with the facilities to excute this work.

We also record our special gratitude to all physicians and all nurses working in the study hospital.

\section{REFERENCES:}

1. Alamri SA, Jaizani $R$ A A, Naqui AA, Ghamdi MSA. Assesment of Drug information Service in Public and Private Sector tertiary care hospital in the Eastern Provine of Saudi Arabia ;Inj Pharmacy 2017,(5)37.

2. Bhavsar R, Zachariah S, Thomas D , Kannan SM. Evaluation of drug information services in a rural secondary level care hospital, Anantapur, AP.J Pharm BioallSci 2012;4:302-6.

3. Jeevangi VM, Neelkantreddy p, Anand B G, Hinchageri SS, Manjunath G, Shantveer H . Assessment and evaluation of drug information service provided by pharmacy practice department based on enquirer perspective .Int .Res .J.P harm 2012,3(10).

4. George B, Rao PGM, Assessment and evaluation of drug information services provided in a South Indian teaching hospital .Indian J. Pharmacol,2005;37(5):315-8 .

5. Wang F, Troutman WG, Scot .Drug information education in Doctor of pharmacy program , Am J Pharm Edu, 2006:70(3):1-4.

6. Rajanandh MG, Varghese R, Ramaswamy C. Assessment of drug information services in a south Indian tertiary care hospital in Kanchipuram district. Int Jpharm pharmSci, 2011;3(3):273-6.

7. Chhetri AK, Palaian S, Mishra P. Drug information services in Nepal : The changing perspectives Kathmandu Univ Med J , 2008 :6(1):117-21.

8. Adibe MO. Assessment of attitude and behavior of health professionals towards provision of drug information services in Enugu State .Int J Dev Res 2010;2:555-64.

9. Venkataraghavan S, Rama M, Leelavathi DA. Performance of a Drug information centre in a South Indian teaching hospital. Int J Pharma Tech Res.2010,2(11).

10. Pradhan SC. The performance of drug information center at the university of Kanas Medical center, Kanas city, USAExperience and evaluation. Indian $\mathrm{J}$. Pharmacol 2002;34:123-129. 